\title{
DEVELOPING A FRAMEWORK TO EVALUATE INDIVIDUAL LeARning in Engineering Design Problems - PART 2: ASSESSMENT OF INDIVIDUAL LEARNING IN TEAM ENVIRONMENTS
}

\author{
Nishant Balakrishnan \\ Centre for Engineering Professional Practice and Engineering Education \\ Faculty of Engineering, University of Manitoba \\ Nishant.Balakrishnan@UManitoba.ca
}

\begin{abstract}
Engineers often model their teaching based on how they expect students to function once they graduate, and as a result they typically have a strong affinity for Problem-Based Learning (PBL) and Team-Based Learning (TBL) approaches. In many cases, this works quite well and has been proven to increase student engagement and performance of design teams. At the same time, as more of the curriculum relies on group projects, there is a simple dilemma that is created: how do you ensure that the learning outcomes a team demonstrates are accurate reflections of what each individual in the team is learning? This rarely poses a challenge in engineering practice, as engineers are expected to specialize, but in an outcome-based accreditation, this can become a serious issue if there isn't a careful consideration of this in the structure of TBL courses. This paper explores the application of an evaluative framework to a course with strong PBL and TBL components that is set up to ensure that students are not only exposed to all learning outcomes as they tackle a project, but are individually evaluated on their ability to show competence in these outcomes. The prime methodology of this framework is an evaluative tool called an "open-ended design exam" that uses a 1:1 mapping of team and individual learning, with scaffolding in the course frameworks to support this. This paper presents application of this approach to two courses developed at the University of Manitoba, outcomes and responses to the course layout, and suggestions for extensions to other courses or programs.
\end{abstract}

Keywords: Problem-based learning (PBL), Team-based learning (TBL), Experiential learning, Engineering design, Open-ended design problems.

\section{INTRODUCTION}

As engineering educators, we often lean heavily on problem-based learning (PBL) and team-based learning (TBL) as both of these classroom environments effectively mimic how an engineer is expected to operate in practice.
In almost any workplace, engineers are expected to collaboratively solve problems, sometimes even with people external to their workplace such as vendors, designers, or contractors. This is a concept that is not just reinforced by individual educators, but is a major portion of the Canadian Engineering Accreditation Board's (CEAB) $12^{\text {th }}$ graduate attribute: Teamwork and Individual. As we see growing trends towards project work (and more specifically group project work) in engineering programs, more and more learning outcomes in design-heavy courses are solely evaluated in a PBL or TBL environment, or even a combination. Typical design-heavy courses like cornerstone or capstone courses can often have no individual assessments, mainly relying on evaluating all of the required objectives in group projects.

At face value, this is a simple problem that most instructors have a simple solution for: determine if each person is contributing to the team. In a real workplace, performance reviews and a close interaction with workers mostly eliminates this problem, but in an educational setting, nearly every PBL or TBL practitioner has encountered students who are not engaged in their team. The most basic solution is to have each team member evaluate each other team member on their performance. This can range from a simple assessment to determine that the team is happy with each member getting the same mark, or can be a multi-stage process that is stitched into the course on a continual basis.

There is however a more subtle problem that exists within TBL that often times is not considered. The problem is that there is not necessarily a link between what tasks a team is capable of achieving and what tasks each individual has actually achieved. In an accreditation context, the plainer question is: if you rely on team work primarily to meet specific learning outcomes in a course, how do you ensure that each student in a team meets each learning outcome? A peer evaluation might seem like an answer, but ultimately most peer evaluations focus on evaluating if the distribution of work is fair, not that the learning outcomes are divided so that each student is exposed to them. 
The simple solution to this it to ensure each student individually does each task, but the conceptual problem with this is that this is not how engineering practice typically works. In a typical industrial setting, the expectation is that a team should work together to ensure the overall team performs well. This could mean that in a multidisciplinary team, some aspects of a problem are solved solely by a subset of a group or even a single person. Professionals work to their strengths, focusing their energies on contributing to the area of the project they are most equipped to handle. From a teaching perspective, this introduces a significant hurdle: if a team completes a project with specific learning outcomes, how do you ensure everyone in the team reaches each outcome? We need to distinguish between what a problem can teach and what it does teach as outlined in [1]. Teams can also differ in their approach to a problem unless that approach is guided through scaffolding [2]. This can be a challenging task, since team members typically split projects so members can take on work they are competent in and avoid tasks requiring further learning. To solve this, teachers can aim for work distribution in a team to be equal in terms of content rather than equal in terms of effort. This changes the function of the team [2], enabling cooperative learning [3]. In order to get students to work in this cooperative learning role, a simple framework for evaluation was developed that incentives [2] students to meet each learning outcome as a team: the open-ended design exam.

\subsection{Background}

At the University of Manitoba, one course that heavily drew on PBL is the former MECH 2012 course, a secondyear undergraduate design course that focuses on having students solve real-world problems in a team and problembased learning environment [4]. This course was redeveloped in 2015-2016 into a scaffolded design course with a structured PBL approach that ensured students could still explore open-ended designs, but also be exposed (experientially) to a variety of specific learning objectives in the process of doing so as evidenced in [1] [5]. This redevelopment is covered in Part 1 of this paper [6]. In doing the redevelopment, one of the main problems that surfaced was that the course redevelopment had taken great efforts to ensure that learning outcomes from team to team could be kept somewhat consistent (while still keeping the design open-ended), but there was no system to encourage each student to achieve each learning outcome. From previous course experience, the natural way for students to divide the work for the course was to divide up the deliverables equally. If a prototype required technical design, computer-aided design (CAD) modelling, drawings, reports, and other deliverables, many teams would split up the work so that each member did the portion they were most adept at. While a peer evaluation might be able to ensure that the work was split up equally, there was no real motivation for students to learn and develop skills they were weak at even if in the end the team was able to collectively have the skills. This is the nature of TBL [2], so a major overhaul of the course itself was introduced to provide a solution to this.

\section{METHODOLOGY}

One of the core ideas of the proposed methodology is that there must be a balance between teams operating in the way that is most effective for them and in a way that promotes each person in the team to learn. A basic guideline that drives the method is that students are all at different levels before approaching the design problem, but after working together, the framework should promote students to work and learn collaboratively [3]. This puts the expectation that a team may not equitably split up work as they approach a design problem, but by the time they are finished, each member in the team should be able to solve the same design problem themselves. Although each student can't demonstrate this on an already completed project, an exam that tests the same learning outcomes as the project in an open-ended manner could be given to each student to see if the students have in fact learned the required outcomes that are scaffolded into the project itself. One cause for this is that students will often strive to accomplish a task without regard for the learning objectives they are given unless the tasks have the learning outcome as a focus [5]. One solution to this is covered in the section below.

\subsection{Open-Ended Design Exams}

The open-ended design exam is an outcome-based exam that tests individual students on specific design skills that are embedded into design projects. Courses can be set up so that the exam weights are similar to project weights with the expectation that exam marks will typically be lower than group marks. In order to ensure that a student passing the course also has the required outcomes, a minimum passing grade can be set on the exam that also serves as a passing grade in the course.

Ideally, both the project work scaffolding and the exam questions are derived from the same learning outcomes and both require an understanding of skills embedded within project work. To emphasize this, lecture content should be clearly laid out to set up the knowledgebase for the course, but the actual ability to apply the skills should be developed in projects and tested through project performance and exams. This means that the same learning outcome is covered in multiple places: it's talked about at length in the lectures, it's distilled down to a simpler evaluation of the base learning requirement in the projects, and it's tested at the appropriate level (as defined by the Bloom's taxonomy [7] definition of the outcome on the framework) in an exam setting. This also means that a student (if attendance is evaluated in some way) is exposed to the learning outcome in a lecture 
setting, and allowed a chance to reinforce the learning experientially (in a collaborative learning environment). If a tutorial or similar setting also exists, there can be assignments, labs or tutorials that also provide more opportunities to practice the same skills.

In theory, if this is set-up as outlined, the exams themselves should be "no-load" examinations: if students have gone through the process and learned the required outcome, they should be able to repeat the same task given a similar situation without needing to prep for the exam. This can obviously vary for certain technical learning outcomes, but careful question design can also help promote this idea.

\subsection{Course Implementation}

To apply this approach, the framework for creating simulacra of real-world design problems as covered in [6] was used to apply the open-ended design exam to a pair of cornerstone design courses, one in Biosystems Engineering and one in Mechanical Engineering at the University of Manitoba.

Both of these courses focused on engaging students in carefully constrained and scaffolded real-world problems with local significance. The courses had different expectations and projects, but followed a similar schedule. Mechanical students were tasked with prototyping HVDC line de-icers while Biosystems students created autonomous algae bloom skimmers.

In each course, the problems (although drastically different to the layperson) are constrained carefully to expose students to different levels of the same basic learning outcomes. The expectation in the Biosystems course is that each group emerges as a group that is capable of applying mechanical design principles to a relatively straightforward mechanical design problem, while the goal in the Mechanical course is to have the students be able to tackle much more complicated problems. Part of the difference in the difficulty in the courses are the specific learning objectives. For example, in the Biosystems course, very few parts of the prototype are under load, so while the students are expected to be able to come up with ways to fasten power transmission parts together in a plethora of arrangements, the quality of their designs can be lower and still function to meet the constraints of the problem. In the mechanical course the project is set up to load most key connection points, so the quality of the design must be much higher to avoid having the prototype collapse under load. In both courses the topics of bolted connections and machine structure is covered, but the expectation of the Biosystems course might be only to identify or explain a situation where load can affect a bolted connection while the equivalent learning outcome for the Mechanical course would be to apply the fundamentals of machine structure design to a given joint to have it carry a significant force through it.
As an example of this that is covered in [6], a learning objective for the course, a specific evaluated outcome, a project constraint that forces students to meet the outcome in their project and an example of a test question are listed below:

- Learning Objective 7: Understand and apply the concept of manufacturing tolerance to the design of mechanical parts.

- Outcome 7.1: By the end of the term, students should be able to understand how to determine the manufacturing tolerance of a specific process and be able to produce parts with a functional fit such as a clearance fit.

- Project Constraint: Provide machined (high precision) shaft components for student designs that must interface with only laser cut (moderate precision) or $3 \mathrm{D}$ printed (low precision) parts.

- Evaluation: Ask students on the exam to provide the steps they'd use to determine the tolerances of various parts of a shaft produced using similar processes to those used in their projects, and to work through the process to design a part that can be made from different processes (with prescribed tolerances) to fit that shaft.

Questions on the exams can vary: from simple knowledge checks to a long open-ended design question that takes the student through a design problem scaffolded in a similar manner as their project [1]. Within the context of the exam, students have wildly different answers and solutions (much like their project) but the rubric (much like their project work) is based on the student's approach to design. In order to achieve a high score on the exam, students must have a thorough knowledge of all aspects of their group project, but ultimately most of the questions can't be explicitly studied for like a typical exam. To use the question above as an example, the logical method to study for the question would be to gain practice to the application of the tolerance to the parts in question, which would be provided amply through project work.

In the simplest case, a multiple-choice short answer section can be used to evaluate most simple learning outcomes, but often these questions are hard to generate. It's straightforward to generate lots of short answer questions, but the "no-load" style of examining also requires questions to be about items you expect a student to know about for their lifetime. If one asks a question about a specific tool used to make a part, likely you would be evaluating a student's ability to remember a process, but if you asked them to walk through a design situation, you are instead asking them to rely on knowledge they should have internalized.

In both the Mechanical and Biosystems courses, the mark distribution sets approximately $45 \%$ of the final mark 
based on these open-ended design assessments with approximately $40 \%$ of the mark coming from the design projects themselves. This transforms the project from a primary evaluation component to something more along the lines of practicum in design, an approach that has been evidenced to work well in a variety of experiential courses such as the one in [8]. The rationale is that in a typical situation, the project marks are higher and the individual marks help to differentiate between what students have learned. In both courses, the exams are set up with the requirement that students must pass them to earn a passing grade in the course, which also sets a minimum bar for the level of individual learning a student must show in order to pass the course. Some of the approaches used in the evaluation in the Mechanical and Biosystems courses are to clearly define sections of the exam that draw on different types of questions. A short answer section is comprised mainly of questions that draw on learning outcomes that are lower on Bloom's taxonomy [7] and require simpler evaluation. For example, if students are taught about different types of fasteners, identifying a specific type they should have used in the project in a specific context (if there's also a project constraint that forces the same outcome to be evaluated in the project) could be a valid multiple-choice question to test the exposure to the outcome. A "short-ish" answer section was developed to test questions that students might have been exposed to, but also cannot be necessarily required to remember without reasoning. An example of this might be (for mechanical design) a topic like minimum constraint design, where students are taught a "way of thought" and might be expected to recall the approach in general and be able to apply it in a design context. Long answer questions can vary quite a bit course to course, but typically call on a string of questions that walk the student through a design problem that shares a similar scaffold and constraint matrix to the problem they worked on during the term. At this point in the exam, answers can vary broadly as students can come up with different ideas and approaches, but ultimately their overall approach to questions is marked. This can test learning outcomes that are higher on Bloom's taxonomy, such as deriving/selecting/justifying design decisions in the context of a design problem. Finally, the exam will also typically ask for reflection on existing designs, i.e. students will typically be asked to look back to their design projects and re-engineer a portion or reflect on lessons referring to their specific projects. These are again items that the student is expected to remember, having spent the prior 13 weeks working on designs, and be able to walk through similar design challenges in an exam setting. Through this process, the exam ends up being approximately $60 \%$ by weight entirely open-ended, where one exam picked up can be totally different in almost every answer compared to the next, but with some shared approaches.
The overall goal of setting an exam like this is twofold: to establish which students in a group were exposed to the aspects of design expected in the prototype, and also to benefit students who may or may not have had a successful prototype for reasons beyond their control. The course is designed carefully from a heuristic basis for the mark cut offs such that over several years it's technically possible for a student to have a project that is not successful but have the student still receive a high grade, but only in the rarest of occasions.

\section{OUTCOMES AND RESPONSE}

Since the initial course concept, the course has been offered twice a year for Mechanical Engineering students and once a year for Biosystems Engineering students from 2016 to present. Each cohort has been faced with a unique open-ended exam with different design challenges present. Each exam is carefully tailored to match the level of expected competency in the learning outcomes tested for the given course with the Biosystems course exams by default being easier.

Students going through this program have had a success rate of anywhere between $90-98 \%$ in any given year, with only a few students not passing the course. From the start of the course to the end, the need to distribute work equally not equitably is strongly impressed on the students and has usually shown up on the final exam. From an educator standpoint, although peer evaluations are also used, the exam has often shown outliers that clearly have not been involved in all aspects of the design but were still contributing equitably to the group's performance.

\subsection{Student Perspectives}

Students who were exposed to the new course (starting in 2016) were quite alarmed by the exam as there are few exams that students take where review may or may not be helpful to students on a case by case basis. Many students are thrown off initially by the exam, but most end up going through it without problems. One comment routinely received is that students have timing issues with the exam, so the exam is almost always set to provide more time than students require. Overall, most students end up with a slightly lower mark than they get on their project marks in the exam, with some of the students with developed design capabilities and also having good exam writing abilities getting a higher individual exam mark. In most cases, because the mark cut-off has been selected carefully to account for this, the end grades have significant binning: there are clear A+'s, A's and B+'s in the course, which most students expect. For marks below that the course is largely bimodal, where the combination of the cut-off and the evaluation style produces marks that drop significantly, creating few B's and C+'s with a group sitting at the C, D, and $\mathrm{F}$ range. This cut-off is often interpreted well by students as it reflects the idea that the course content is 
either understood or not, and is similar to the way a practicum course might be structured. Rarely in the course have there been student mark complaints as the mechanisms for evaluation and the course itself make the requirements and outcomes fairly clear to students.

\subsection{Industry and Staff Perspectives}

The response from both industry and staff to the course has been exceptional, as the course has to some extent served as a practicum course. In the Biosystems course, for example, employers can know that a Biosystems student from the University of Manitoba is capable of not only working with CAD software but also capable of developing simple, functional designs that involve basic design elements of power transmission, machine structure, and catalog engineered parts, and are capable of developing parts and drawings. Because the course is set up in a manner that enforces students to learn these skills, employers who might not normally hire Biosystems engineers have been open to do so based on the course redevelopment. In the case of the Mechanical class, employers expect many of these capabilities from Mechanical students, but now in upper year courses a solid basis has been provided to develop further skills. As an example of this, a $\mathrm{U}$ of $\mathrm{M}$ Mechanical fluids course (MECH 3492) builds off the CAD design knowledge of students in the course to develop CFD analysis skills. Likewise, Mechanical courses 3502 and 3652 (stress analysis and design and machine design) build off students' ability to build models to introduce topics such as FEA based on the level of competency guaranteed by the cornerstone level courses. The reception from upper year course instructors has been welcome, as the goal of a lower year course is more focused on developing fundamentals and normalizing skills, so students are prepared for more focused courses in upper years.

\section{FUTURE WORK AND SUGGESTIONS}

As the courses develop in the future, the plan is to refine the assessments to include more aspects of the courses themselves. In any TBL course, the core competencies can almost always be tested in a no-load manner if the skills are meant to be individual skills and are carefully developed in a manner that encourages evaluation later. One example of this in the course is the current CAD skills of students. Students currently work through tutorials/labs/assignments that develop their skill in CAD software, but the evaluation of students' skills is only outcome-based. This means that a student who doesn't know how to use the software well can take time and carefully learn the skills required (ideal) or carefully learn how to do the assigned work (not ideal) given enough time. Although this doesn't have to be a problem, in a design course, the distribution of work assumes that each team member has the skill to design parts in a reasonable time, and over a few years it has become clear that some students aren't able to learn the software, don't see value in learning the skills, and end up failing the course as a result. To avoid this an example of a "no-load" test that's being investigated is a software lab exam, where students are required to show their proficiency at the skills they're required to have, but in an individual timed manner.

The other plans for the course primarily include developing more technical content and expansion. As of 2019 , the course now covers some fundamental aspects of stress analysis, to help bridge the gap into later courses that require that same knowledge. Using the same evaluative framework, it was quite straightforward to deliver a module on FEA and stress analysis, and also evaluate students on how much they retained from it.

\subsection{Suggestions and Plans for Expansion}

A common comment from students is about the simplicity of "no-load" exams. In many cases students seem to enjoy the concept of working hard in a project and having the exam test similar outcomes rather than testing course content that might only be presented in lecture notes. From an administrative perspective there is also a major advantage to this, in that there is a now a check and balance in a course where there is significant teamwork. It would be possible to adapt this framework to other teamwork-heavy courses and help alleviate some of the issues associated with teamwork (like most capstone courses). An example of where this framework will be extended is to the upper year Mechanical technical electives at the University of Manitoba that explore topics in computer-integrated manufacturing and automation. These courses largely focus on teamwork, but with the deliverables in the courses there is often grade shifting done via peer evaluations that is required to account for students who only focus on one aspect of the assigned project and have not acquired a competence in the required content.

\section{CONCLUSIONS}

The basic suggestions from this paper are quite simple in nature but are complex to implement. In most cases, when projects are heavily relying on TBL to teach students outcomes in a course, there is no guarantee that students are learning (individually) what they are learning as a team. To put in place a framework that does this, one first needs to carefully define problems so that the learning outcomes are clearly delineated and also evaluated as a group as explained in [6], and then there should be a framework to provide a 1:1 confirmation that students are not only exposed and competent at outcomes in a group, but also equally competent individually. If all of these tasks are achieved, the main benefits of PBL and TBL can be 
harnessed by a course without many of the downsides associated with each.

\section{Acknowledgements}

I would like to acknowledge the contributions of D. Kuhn of the Mechanical Engineering Department at the University of Manitoba and both D. Ruth and M. Friesen (and both of their respective NSERC Chairs in Design Engineering) of the Centre for Engineering Professional Practice for their support of both the mechanical and Biosystems courses. I'd also like to thank J Seniuk-Cicek and R. Balakrishnan for their guidance on the paper.

\section{References}

[1] Brigid J.S. Barron, et al. "Doing with understanding: lessons from research on problem- and project-based learning," Journal of the Learning Sciences, vol. 7, no. 3-4, pp. 271-311, 1998.

[2] David W. Johnson and Roger T. Johnson, Learning Together and Alone: Cooperation, Competition, and Individualization. Englewood Cliffs, N.J: PrenticeHall, 1975, 214 pp. \{ISBN: 978-0135279526\}

[3] Shri Ramaswamy, Ilene Harris, and Ulrike Tschirner, "Student peer teaching: an innovative approach to instruction in science and engineering education," Journal of Science Education and Technology, vol. 10, no. 2, pp. 165-71, 2001.
[4] S.Balakrishnan and C.Laing, "Integration of Computer Aided Design and Manufacturing at Second Year level in Undergraduate Program" in Proc. CEEA Canadian Engineering Education Conf., CEEA11, 6-8 June 2011, St.Johns, Newfoundland.

[5] Alice Y. Kolb and David A. Kolb. "Learning styles and learning spaces: enhancing experiential learning in higher education," Academy of Management Learning \& Education, vol. 4, no. 2, pp.193-212, 2005.

[6] Balakrishnan, Nishant "Developing A Framework to Evaluate Individual Learning In Engineering Design Problems - Part 1: Teaching Through Simulacra Of Real-World Problems," in Proc. 2019 Canadian Engineering Education Association Conf., CEEAACEG19, 9-12 June, Ottawa, Ontario.

[7] Lorin W. Anderson, David R. Krathwohl, and Benjamin S. Bloom, A Taxonomy For Learning, Teaching, And Assessing : A Revision Of Bloom's Taxonomy Of Educational Objectives. New York, NY: Longman, 2001, 352 pp. \{ISBN: 978-0321084057\}

[8] Pete Hylton and Wendy Otoupal-Hylton, "Teaching Applied Engineering Through Practicum Courses," in Proc. 2014 ASEE Annual Conference and Exposition, June 15-18, Indianapolis, IN. 